\title{
Research of different adjuvants and yeast dosages in honey fermentation process
}

\author{
${ }^{1}$ Şarba, Andreea Cristina-2 Timar, Adrian- ${ }^{1}$ Mărghitaş, Liviu Alexandru \\ ${ }^{1}$ University of Agricultural Sciences and Veterinary Medicine, Cluj-Napoca, Romania \\ ${ }^{1}$ University of Oradea Faculty of Environmental Protection, Oradea, Romania \\ andreea.sarba@yahoo.com
}

SUMMARY

\begin{abstract}
In order to ferment honey it is necessary to add in the fermentation environment some substances with the role of adjuvants, to improve the honey must composition and to help the fermentation process. There were tested 2 different combination of adjuvants which were analyzed in the fermentation process. Also the physical and chemical properties of the final products were analyzed. After establishing the most suitable mix of adjuvants it was necessary to test the right dosage of the yeast used to metabolized sugars: Saccharomyces cerevisiae, in order to obtain appropriate organoleptic properties.
\end{abstract}

Keywords: mead, adjuvants, Saccharomyces cerevisiae, honey fermentation

\section{INTRODUCTION}

Honey must represents a fascinating environment totally unexplored, its fermentation being different by grape must fermentation. We can characterize honey must as being a difficult medium for fermentation due to its sugar content which is approximately three times higher than the grape must. The biochemical composition varies from one to another type of honey being directly influenced by changes in environmental factors - is difficult to obtain from a batch to another a finished product that meets the same biochemical and sensory characteristics. Because of this variables a lengthy and rigorous study is required to examine the depth and aspects that affect the production of mead, researching the raw material and the affecting factors ending with the production process and how it can be optimized (Şarba et al. 2014). A mix of adjuvants it is necessary to help the yeast, and provide the nitrogen necessary in sugar metabolization. Also, by increasing the pitching rate, the amount of suspended yeast cells added to a batch, can save time in the fermentation process. However it could also have deleterious side effects on the fermentation performance or on the flavor profile of the final beverage (Verbelen et al. 2009).

\section{MATERIAL AND METHODS}

In this experiment it was used polyfloral honey. Two different adjuvants mix were tested. The first mix contained: ammonium sulfate $35 \%$, diammonium phosphate $60 \%$, potassium bicarbonate $4,8 \%$, vitamin
B1 $0.2 \%$. The composition of the second mix was: ammonium hydrogen phosphate $10 \%$, potassium metabisulphite $60 \%$, ammonium phosphate dibasic $15 \%$, bentonite $15 \%$. The two variants of additives are different in terms of physical-chemical combination of different substances with the sole purpose of obtaining a superior product. Saccharomyces cerevisiae was used as yeast in the fermentation process.

In order to determine the quality of the sample of honey we used to obtain mead, we had to determine individual sugar spectrum by using HPLC-RID method (Bogdanov et al. 1997) on a Shimadzu instrument with refractive index detector, amino silica gel modified column Alltima Amino. For a safe fermentation process, honey was sterilized using UV lamps. For confirming the success of sterilization process, honey was inoculated on DRBC agar cultures. Honey must was inoculated with selected wine yeast strain Saccharomyces cerevisiae. Alcohol content was determine during the fermentation process by using the SR 184-2:2010 standard method for ethyl alcohol and alcoholic drinks (determination of alcoholic concentration) with Kjeldahl steam distillation unit.

\section{RESULTS AND DISCUSSION}

After the fermentation process was over, final products were analyzed. The results of sugar metabolization conducted by Saccharomyces cerevisiae for each sample enriched with the 2 different mix of fermentation adjuvants are presented in Table 1.

Comparison of sugar content after fermentation with 2 adjuvants

\begin{tabular}{|c|c|c|c|c|c|c|c|c|c|}
\hline Details & $\begin{array}{c}\text { Fructose } \\
(\%)\end{array}$ & $\begin{array}{c}\text { Glucose } \\
(\%)\end{array}$ & $\begin{array}{c}\text { Sucrose } \\
(\%)\end{array}$ & $\begin{array}{c}\text { Turanose } \\
(\%)\end{array}$ & $\begin{array}{c}\text { Maltose } \\
(\%)\end{array}$ & $\begin{array}{c}\text { Trehalose } \\
(\%)\end{array}$ & $\begin{array}{c}\text { Isomaltose } \\
(\%)\end{array}$ & $\begin{array}{c}\text { Erlose } \\
(\%)\end{array}$ & $\begin{array}{c}\text { Total sugars } \\
(\%) \\
\end{array}$ \\
\hline Honey must & 11.50 & 7.79 & 0.04 & 0.68 & 0.47 & 0.19 & 0.20 & 0.45 & 21.32 \\
\hline M1 mix & 0.10 & 0.04 & - & 0.26 & 0.44 & 0.16 & 0.11 & - & 1.02 \\
\hline M2 mix & 11.33 & 8.31 & - & 0.25 & 0.35 & 0.16 & 0.08 & - & 20.48 \\
\hline
\end{tabular}

Note: M1 mix: ammonium sulfate $35 \%$, diammonium phosphate $60 \%$, potassium bicarbonate $4.8 \%$, vitamin B1 $0.2 \%$; M2 mix: ammonium hydrogen phosphate $10 \%$, potassium metabisulphite $60 \%$, ammonium phosphate dibasic $15 \%$, bentonite $15 \%$. 
M1 helped the yeast to carry out the fermentation, the sugars are converted into alcohol, resulting in a product with alcohol $13.65 \% \mathrm{v} / \mathrm{v}$ ( $\rho$ 0.9823). Sugars, in particular fructose and glucose have been converted to an extent of more than $95 \%$. When fermented by M2 samples the percentage of sugars was about $4 \%$. In case of M2 the fermentation process was incomplete, inappropriate parameters were recorded resulting in the final product alcohol concentration of $0.06 \%$ ( $\rho 0.999)$. The samples were fermented in similar environmental condition, from the same type and batch of honey, with the same dosage of yeast $\left(0.30 \mathrm{~g} \mathrm{l}^{-1}\right.$ Saccharomyces cerevisiae).

After establishing the proper adjuvant for the fermentation process, we observed that the dosage of Saccharomyces cerevisiae used previously was too high, and the product had fault flavor profile. Consequently the right dosage must be established. In order to do that, there were teste 3 different dosages of Saccharomyces cerevisiae: $0.15 \mathrm{~g} \mathrm{l}^{-1}, 0.20 \mathrm{~g} \mathrm{l}^{-1}, 0.30 \mathrm{~g} \mathrm{l}^{-1}$. All physical and chemical parameters were analyzed (Table 2-3).
In all three dosages that were tested, sugars fermented almost entirely. Sugar degradation values were very close: sample inoculated with $0.10 \mathrm{~g} \mathrm{l}^{-1}-78 \%$ carbohydrates percentage degradation; sample with $0.15 \mathrm{~g} \mathrm{l}^{-1}$ $-83 \%$ degradation and sample inoculated with $0.20 \mathrm{~g} \mathrm{l}^{-1}$ $-82 \%$ by degradation of the carbohydrates by the data in Table 2.

In general the process of fermentation of sugars by yeast is influenced by the $\mathrm{pH}$ of the honey must. The $\mathrm{pH}$ may be considered a measure of the fermentation process due to the fact that the yeast does not ferment at a low $\mathrm{pH}$. Initial $\mathrm{pH}$ value of the wort honey (3.82) decreased gradually during the fermentation, reaching values of 2.80 for the samples inoculated with $0.10 \mathrm{~g} \mathrm{l}^{-1}$ and $0.15 \mathrm{~g} \mathrm{l}^{-1}$, respectively 3.08 for sample with the dosage of $0.20 \mathrm{~g} \mathrm{l}^{-1}$.

In terms of the higher alcohol concentration had a second sample $\left(0.15 \mathrm{~g} \mathrm{l}^{-1}\right)-10.18 \% \mathrm{v} / \mathrm{v} ; 9.94 \% \mathrm{v} / \mathrm{v}$ (the sample inoculated with $0.20 \mathrm{~g} \mathrm{l}^{-1}$ ) and $9.37 \% \mathrm{v} / \mathrm{v}$ (the sample inoculated with $0.10 \mathrm{~g} \mathrm{l}^{-1}$ ).

Metabolization of sugars

\begin{tabular}{lccccccccc}
\hline \multicolumn{1}{c}{ Details } & $\begin{array}{c}\text { Fructose } \\
(\%)\end{array}$ & $\begin{array}{c}\text { Glucose } \\
(\%)\end{array}$ & $\begin{array}{c}\text { Sucrose } \\
(\%)\end{array}$ & $\begin{array}{c}\text { Turanose } \\
(\%)\end{array}$ & $\begin{array}{c}\text { Maltose } \\
(\%)\end{array}$ & $\begin{array}{c}\text { Trehalose } \\
(\%)\end{array}$ & $\begin{array}{c}\text { Isomaltose } \\
(\%)\end{array}$ & $\begin{array}{c}\text { Erlose } \\
(\%)\end{array}$ & $\begin{array}{c}\text { Total sugars } \\
(\%)\end{array}$ \\
\hline Must & 11.50 & 7.79 & 0.04 & 0.68 & 0.47 & 0.19 & 0.20 & 0.45 & 21.32 \\
$0.10 \mathrm{~g} \mathrm{l}^{-1}$ & 2.94 & 0.56 & - & 0.33 & 0.48 & 0.18 & 0.18 & - & 4.67 \\
$0.15 \mathrm{~g} \mathrm{l}^{-1}$ & 2.16 & 0.32 & - & 0.30 & 0.47 & 0.18 & 0.20 & - & 3.63 \\
$0.20 \mathrm{~g} \mathrm{l}^{-1}$ & 2.36 & 0.35 & - & 0.29 & 0.48 & 0.19 & 0.20 & - \\
\hline
\end{tabular}

Table 3.

Physical and chemical parameters of the final products

\begin{tabular}{lccccc}
\hline \multicolumn{1}{c}{ Details } & $\begin{array}{c}\text { Acidity } \\
\left(\mathrm{meq} \mathrm{kg}^{-1}\right)\end{array}$ & $\mathrm{pH}$ & $\begin{array}{c}\mathrm{HMF} \\
\left(\mathrm{mg} \mathrm{l}^{-1}\right)\end{array}$ & $\begin{array}{c}\text { Polyphenols Flavones } \\
\left(\mathrm{mg} \mathrm{l}^{-1}\right)\end{array}$ & \begin{tabular}{c}
$\left(\mathrm{mg} \mathrm{l}^{-1}\right)$ \\
\hline Must
\end{tabular} \\
\hline 98.10 & 3.40 & 0.42 & 61.78 & 8.78 \\
$0.10 \mathrm{~g} \mathrm{l}^{-1}$ & 105.61 & 2.80 & 2.56 & 80.25 & 7.97 \\
$0.15 \mathrm{~g} \mathrm{l}^{-1}$ & 105.80 & 2.80 & 2.51 & 81.44 & 8.90 \\
$0.20 \mathrm{~g} \mathrm{l}^{-1}$ & 107.33 & 3.00 & 2.43 & 79.40 & 8.55 \\
\hline
\end{tabular}

In terms of physical - chemical parameters of the wine quality which conforms to the beginning stage of research. Acidity and $\mathrm{pH}$ of the final products within the parameters of $\mathrm{pH}$, in particular very low value recorded (Table 3). During the fermentation, the total acidity of the mash increased and the $\mathrm{pH}$ dropped to value of $2.8-\mathrm{pH}$ threshold of growth and development of the yeast Saccharomyces cerevisiae.

Sensory analysis is the last redoubt of wine in declaring the product as compliant. Sensory impact was noted as practiced by oenological quality assessment score.

It used five-point system assessment, testing nine people attending specialized sector organoleptic tasting; noting the following: overall impression, clarity, color, astringency, acidity, flavor quality, the intensity of the taste, smell. The values of the organoleptic test are found in Table 4.

Regarding all the data above, the dosage $0.15 \mathrm{~g} \mathrm{l}^{-1}$ encounters the best organoleptic properties and physical and chemical parameters.

Sensory analysis results

\begin{tabular}{lcccccccc}
\hline \multicolumn{1}{c}{ Details } & $\begin{array}{c}\text { General } \\
\text { impression }\end{array}$ & Clarity & Color & Astringency & Acidity & $\begin{array}{c}\text { Flavour } \\
\text { quality }\end{array}$ & $\begin{array}{c}\text { Taste } \\
\text { intensity }\end{array}$ & Smell \\
\hline $0.10 \mathrm{~g} \mathrm{l}^{-1}$ & 3.8 & 4.0 & 4.3 & 3.6 & 3.4 & 4.4 & 4.3 & 4.4 \\
$0.15 \mathrm{~g} \mathrm{l}^{-1}$ & 4.3 & 4.5 & 4.6 & 3.9 & 3.5 & 4.2 & 4.2 & 4.3 \\
$0.20 \mathrm{~g} \mathrm{l}^{-1}$ & 4.0 & 4.3 & 4.7 & 4.1 & 3.9 & 3.6 & 3.8 & 3.9 \\
\hline
\end{tabular}

\section{CONCLUSIONS}

Because mead fermentation is a time consuming process that often takes several months to complete, depending on the types of honey, yeast strain and honey-must composition (Navrátil et al. 2001) the purpose of this study was to establish a complex of adjuvants that will resume this time to a few weeks. 
The selected mix of adjuvants (ammonium sulfate $35 \%$, diammonium phosphate $60 \%$, potassium bicarbonate $4.8 \%$, vitamin B1 $0.2 \%$ ) fits very well with the ferment used to produce honey wine. With the right dosage of
Saccharomyces cerevisiae the final product has good organoleptic properties and physical and chemical values, and the fermentation time is reduced to 6 weeks.

\section{REFERENCES}

Bogdanov, S.-Martin, P.-Lullmann, C. (1997): Harmonized methods of the international honey commission. Apidologie. Extra issue. 1-59.

Navrátil, M.-Šturdik, E.-Gemeiner, P. (2001): Batch and continuous mead production with pectate immobilized, ethanol-tolerant yeast. Biotechnology Letters. 23: 977-982.
Şarba, A. C.-Mărghitaş, L. A.-Timar, A. (2014): Influence of Saccharomyces cerevisiae fermentation versus pollen fermentation on mead production. Innovativa. 1: 11-13.

Verbelen, P. J.-Dekoninck, T. M. L.-Saerens, S. M. G.-van Mulders, S. E.-Thevelein, J. M.-Delvaux, F. R. (2009): Impact of pitching rate on yeast performance and beer flavor. Applied Microbiology and Biotechnology. 82: 155-167. 
